\title{
Hysteresis in the gas sorption isotherms of metal-organic cages accompanied by subtle changes in molecular packing
}

Received 00th January 20xx, Accepted 00th January 20xx DOI: $10.1039 / x 0 x \times 00000 x$

\author{
Gavin A. Craig, ${ }^{\text {a }}, *$ Patrick Larpent, ${ }^{\text {a }}$ Hinano Urabe, ${ }^{\text {a }}$ Alexandre Legrand, ${ }^{a}$ Mickaele Bonneau, ${ }^{a}$ \\ Shinpei Kusaka, ${ }^{a}$ and Shuhei Furukawa ${ }^{a, b *}$
}

Structural deformation in response to gas sorption is rarely observed for porous molecular solids, when compared to porous framework materials. Here, we describe the effect of chemical modification on the exterior of lantern-type metal-organic cages on the emergence and then disappearance of cooperative gas uptake. The results suggest that supramolecular design of ligands can be used to reveal this behaviour.

Porous molecular solids are a well-known class of porous materials. ${ }^{1}$ Their composition can be purely organic, as is the case for porous organic cages (POCs), ${ }^{2}$ or based on coordination bonds, as for metal-organic cages (MOCs). ${ }^{3}$ Because the interactions between the individual molecules in the solid state are non-covalent and relatively weak, characterising the gas sorption behaviour of these cages can be complex, and the uptake of gas may not be solely determined by the pore of the molecule. ${ }^{4}$ For instance, the activation processes prior to gas sorption measurements must avoid causing the collapse of the materials into non-porous phases. Consequently, common to both classes of cage are reports that gas sorption properties are sensitive to activation protocols; ${ }^{5}$ as an example, the cuboctahedral $\mathrm{MOC}\left[\mathrm{Cr}_{24}(\mathrm{TBI})_{24}\right]$ ( $\mathrm{TBI}=$ tert-butylisophthalate) was found to be non-porous upon activation at $160^{\circ} \mathrm{C}$, while it showed an uptake of $\mathrm{N}_{2}$ of $387 \mathrm{~cm}^{3} / \mathrm{g}$ at $77 \mathrm{~K}$ and 1 bar of pressure if activated at $200^{\circ} \mathrm{C} .{ }^{6}$ Nevertheless, the weak nature of the intermolecular interactions means that the gas sorption behaviour of the cages can depend on the packing of the molecules in the solid state - this can be rearranged by varying the solvent content of the parent structure, with the resulting

\footnotetext{
a. Institute for Integrated Cell-Material Science (WPI-iCeMS), Kyoto University, Yoshida, Sakyo-ku, Kyoto 606-8501, Japan.E-mail: gavin.craig@strath.ac.uk; shuhei.furukawa@icems.kyoto-u.ac.jp

b. Department of Synthetic Chemistry and Biological Chemistry, Graduate School of Engineering, Kyoto University, Katsura, Nishikyo-ku, Kyoto 615-8510, Japan

+Present address: Department of Pure and Applied Chemistry, University of Strathclyde, Glasgow, UK.

Electronic Supplementary Information (ESI) available: Details of synthetic procedures, Crystallographic data, IR and NMR spectra, further PXRD data, TGA data, gas sorption data, SEM images, and .cifs for $\mathbf{1}$ and $\mathbf{2}$. See DOI: $10.1039 / x 0 x x 00000 x$
}

activated phases showing distinct porosity for the same cage. ${ }^{7}$ In this vein, differing arrangements of the POC molecule CC4 yielded two distinct activated phases, $C C 4 \alpha$ and $C C 4 \beta$, showing contrasting $\mathrm{N}_{2}$ sorption isotherms: $\mathrm{CC} 4 \beta$ displayed Type I uptake, while $\mathrm{CC} 4 \alpha$ presented steps in the adsorption branch. ${ }^{8}$

For MOCs, stepped or hysteretic gas sorption isotherms are rare, ${ }^{9}$ especially when compared to their polymeric counterpart, metal-organic frameworks (MOFs). ${ }^{10}$ Recently we reported the lantern-type ${ }^{11} \mathrm{MOC}\left[\mathrm{Cu}_{4}(\mathrm{EtOL})_{4}\right]$ (EtO-MOC; formula given for the activated phase of the MOC, where $\mathrm{EtOLH}_{2}=3,3^{\prime}-((5-$ ethoxy-1,3-phenylene $)$ bis(ethyne-2,1diyl))dibenzoic acid). ${ }^{12}$ Upon activation from a methanol solvatomorph of EtO-MOC, uptake of $\mathrm{CO}_{2}$ at $195 \mathrm{~K}$ was found to occur with a stepped isotherm and a hysteresis loop, which was attributed to structural deformation of the MOC assemblies in response to gas uptake - so-called gate-opening behaviour. These properties contrasted with the Type $\mathrm{I}$ isotherm reported for the related lantern MOC $\left[\mathrm{Cu}_{4}(\mathrm{~L})_{4}\right]$, where $\mathrm{LH}_{2}$ is $3,3^{\prime}-((1,3-$ phenylene)bis(ethyne-2,1-diyl))dibenzoic acid. ${ }^{11 a}$ Because the composition of the activated phase of these MOCs differed only in the presence of the ethoxy-group attached to the exterior of EtO-MOC, we anticipated that small differences in the exterior functionalisation of the MOCs could tune the cooperative gas sorption of EtO-MOC.

We therefore synthesised two new ligands, 3,3'-((5methoxy-1,3-phenylene)bis(ethyne-2,1-diyl))dibenzoic acid and 3,3'-((5-propoxy-1,3-phenylene)bis(ethyne-2,1-diyl))dibenzoic acid, $\mathrm{MeOLH}_{2}$ and $\mathrm{PrOLH}_{2}$, respectively (see ESI for synthetic details). By using chains of varying lengths, we thought it would be possible to retain cooperative uptake of $\mathrm{CO}_{2}$, but alter the overall capacity of the materials with respect to that observed for EtO-MOC. Using these ligands, two lantern-type MOCs were synthesised: $\quad\left[\mathrm{Cu}_{4}(\mathrm{MeOL})_{4}\left(\mathrm{H}_{2} \mathrm{O}\right)_{2}(\mathrm{DMA})_{2}\right] \quad$ ([MeO$\left.\left.\operatorname{MOC}\left(\mathrm{H}_{2} \mathrm{O}\right)_{2}(\mathrm{DMA})_{2}\right], \mathbf{1}\right)$ and $\left[\mathrm{Cu}_{4}(\mathrm{PrOL})_{4}(\mathrm{DMF})_{2}(\mathrm{MeOH})_{2}\right]$ ([PrO$\left.\operatorname{MOC}(D M F)_{2}(\mathrm{MeOH})_{2}\right], 2$ ), where 1 and $\mathbf{2}$ refer to the assynthesised crystals. Both complexes crystallise in monoclinic space groups: $P 2_{1} / n$ for $\mathbf{1}$, and $P 2 / n$ for $\mathbf{2}$, (Table S1). The MOC 


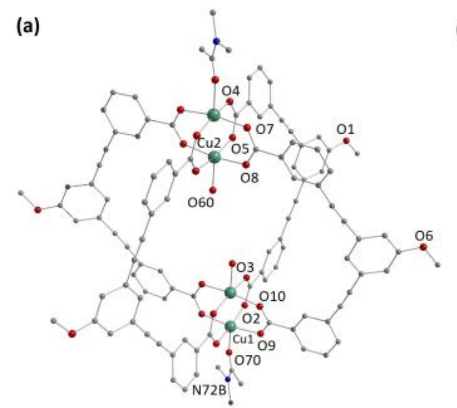

(b)

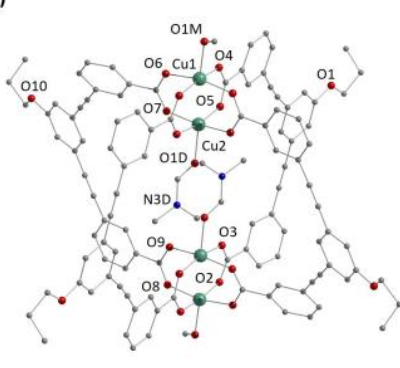

Fig. 1 View of the molecular structures of the MOC units in (a) compound $\mathbf{1}$ and (b) compound 2. Hydrogen atoms have been omitted for clarity, only the major components of disordered moieties are shown, and only crystallographically independent metal ions and heteroatoms have been labelled.

molecules in each case consist of four deprotonated $\mathrm{MeOL}^{2-}$ or PrOL ${ }^{2-}$ ligands connecting two $\mathrm{Cu}(\mathrm{II})$ paddlewheel nodes, with the centre of the molecular pore sitting on a crystallographic inversion centre (Fig. 1).

In 1, the external coordination sites of the paddlewheel are occupied by DMA molecules bound through oxygen atoms, while the interior sites are filled by water molecules. While an analysis of the intermolecular interactions using PLATON ${ }^{13}$ shows that there are no strong $\pi-\pi$ stacking interactions present in the structure (Fig. S1), and neither does the arrangement of the cages lead to channels in the structure (Fig. S2), the overall packing causes a pinching of the cage that leads to two different window sizes of 9.228(7) and 11.415(5) A (Fig. S3).

In 2, the DMF molecules coordinate to the internal axial site of the Cu-paddlewheels, while the smaller $\mathrm{MeOH}$ molecules coordinate to the external axial sites (Fig. 1). The coordination of the DMF molecules inside the cage induces a strain in the complex such that the $\mathrm{Cu}$-Cu paddlewheels on either side of the complex are not aligned (Fig. S4). The strain is accommodated by deformations in the PrOL ${ }^{2-}$ ligands, particularly along the bonds linking the exterior aromatic rings to the central propoxyphenylene ring. As with compound 1, there are no predominant $\pi-\pi$ stacking interactions, or ordered channels found in the lattice (Fig. S5 and S6).

Soaking the bulk powders of compounds $\mathbf{1}$ and $\mathbf{2}$ in methanol led to transformations of their respective crystalline phases (Fig. 2). The effect of solvent exchange on 1 was to yield a phase that strongly resembles the $\mathrm{MeOH}$ phase found previously for EtO-MOC - this phase was associated with cooperative gas adsorption for both $\mathrm{Cu}$ - and Rh-based EtOMOCs (Fig. S7 shows a comparison of the powder X-ray data). ${ }^{12}$ In contrast, the effect on $\mathbf{2}$ is to induce a phase that presents a much lower degree of crystallinity. IR spectroscopy was used to follow these processes and demonstrate that the MOC molecules did not decompose (Fig. S8 and S9). The MOCs were then activated for gas sorption measurements by heating at $120^{\circ} \mathrm{C}$ under vacuum overnight. ${ }^{1} \mathrm{H}$ NMR spectroscopy of aciddigested samples of the activated phases showed that $\mathrm{MeOH}$ present from the solvent exchange process, or DMA or DMF present from the synthesis, had been successfully removed (Fig. S10-S13, and Fig. S14 and S15 for associated thermogravimetric analysis data).

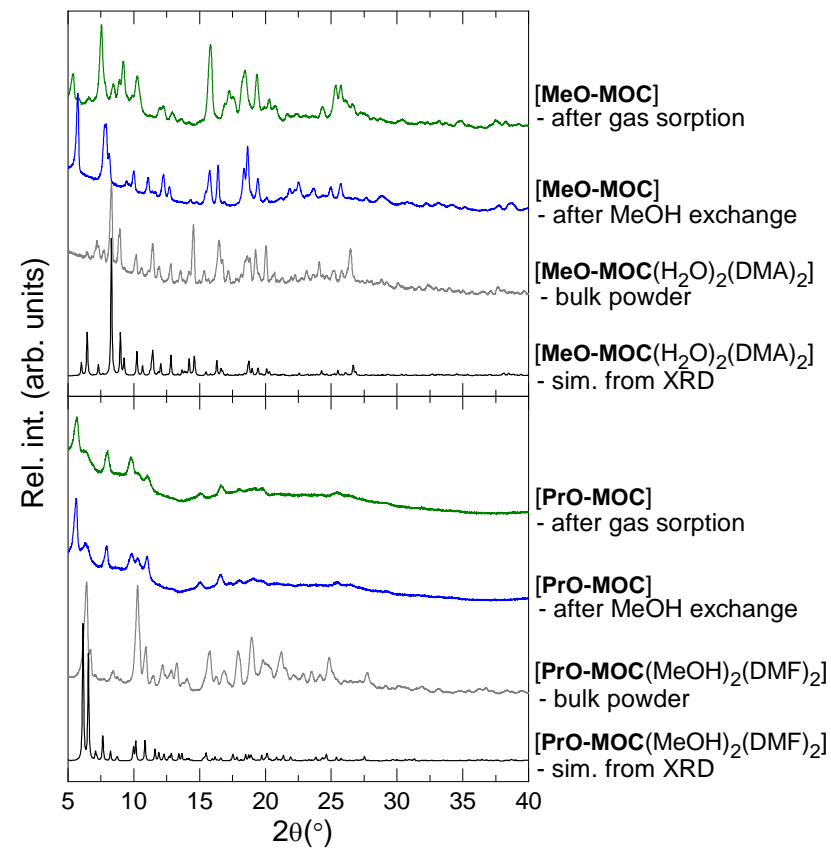

Fig. 2 Powder X-ray diffraction (PXRD) data collected for (top) MeO-MOC and (bottom) PrO-MOC: the simulated diffractograms based on the .cifs for the single crysta structures (black); the diffractograms of the bulk powders (grey); after solvent exchange with $\mathrm{MeOH}$ (blue); and after gas sorption experiments (green).

The gas sorption properties of the activated MOCs MeOMOC (from compound 1) and PrO-MOC (from compound 2) are shown in Figure 3. The $\mathrm{N}_{2}$ gas adsorption isotherm for MeOMOC measured at $77 \mathrm{~K}$ shows a small microporous region, entering a plateau at $P / P_{0} \approx 0.04$. There is a gentle increase in

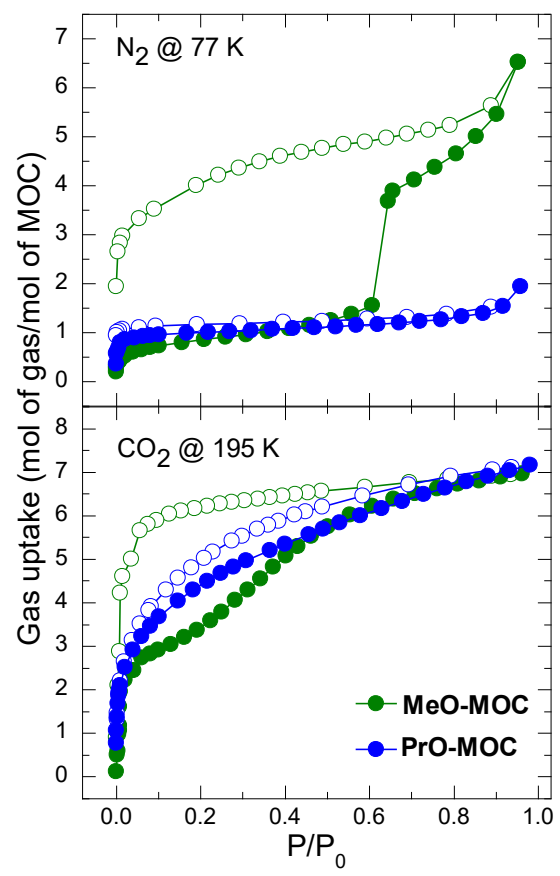

Fig. 3 (Top) Number of moles of $\mathrm{N}_{2}$ adsorbed per mole of MOC molecule as a function of partial pressure for the cages $\mathrm{MeO}-\mathrm{MOC}$ and $\mathrm{PrO}-\mathrm{MOC}$, measured at $77 \mathrm{~K}$, and (bottom) number of moles of $\mathrm{CO}_{2}$ adsorbed per mole of $\mathrm{MOC}$ molecule as a function of partial pressure measured at $195 \mathrm{~K}$. Filled circles represent adsorption, and empty circles represent desorption. 
uptake of $\mathrm{N}_{2}$ with increasing partial pressure until $P / P_{0} \approx 0.60$, where a step is observed and the uptake by the MOC approximately doubles, from 1.6 molecules of $\mathrm{N}_{2}$ to 3.7. The maximum uptake measured at $P / P_{0} \approx 0.95$ was approximately 6.5 molecules of $\mathrm{N}_{2}$ for each molecule of MeO-MOC (79.7 $\mathrm{cm}^{3} / \mathrm{g}$, see Figure $\mathrm{S} 16$ for the sorption isotherm in $\mathrm{cm}^{3} / \mathrm{g}$ ). The desorption branch of the isotherm diverges from the adsorption measurement, showing a continual decrease in the volume of gas uptake until $P / P_{0} \approx 0.30$, where the decrease becomes steeper. This hysteresis loop does not clearly match any single isotherm type described by the IUPAC, especially given the difficulty in categorising this type of flexible material where network effects from the interactions between the molecules will play a role in the structural transition. ${ }^{14}$ The $\mathrm{CO}_{2}$ gas sorption isotherm at $195 \mathrm{~K}$ also features a broad hysteresis loop. At $P / P_{0}<0.01$, there is a steep increase in the volume of $\mathrm{CO}_{2}$ adsorbed as a function of pressure, before an inflection point at $P / P_{0} \approx 0.02$, above which the increase is much more gradual: between $P / P_{0} \approx 0.06$ and 0.96 the gas uptake increases from 33.4 to $85.0 \mathrm{~cm}^{3} / \mathrm{g}$ ( $c a .7$ molecules of $\mathrm{CO}_{2}$ adsorbed for each MOC molecule; the data in terms of $\mathrm{cm}^{3} / \mathrm{g}$ are shown in Fig. S17). In the desorption branch, the step down occurs at $P / P_{0} \approx$ 0.06 , and passes through a shoulder in the pressure range 0.01 $<P / P_{0}<0.04$.

In situ powder X-ray diffraction gas sorption experiments yielded a similar gas sorption isotherm for uptake of $\mathrm{CO}_{2}$, with a slightly more pronounced shoulder in the desorption branch of the isotherm (see Fig. S18). The associated diffractograms show a very gradual change in the peaks in the region of $5^{\circ}<$ $2 \theta<10^{\circ}$, particularly in the strongest reflection at $2 \theta=7.9^{\circ}$ upon uptake of $\mathrm{CO}_{2}$ (selected data are given in Fig. 4). We suggest that these subtle changes to the crystal packing reflect a lower degree of cooperativity in the lattice of MeO-MOC than found for EtO-MOC ${ }^{12}$ or the POC molecule CC $4 \alpha{ }^{8}$ For both of those molecules, in situ powder $\mathrm{X}$-ray experiments revealed sharp structural transitions associated with large steps in the gas sorption isotherms (induced by $\mathrm{CO}_{2}$ for the MOC, $\mathrm{N}_{2}$ for the $\mathrm{POC})$. A comparison of the adsorption branches for MeO-MOC and EtO-MOC is given in the supporting information (Fig. S19). The continuous changes in the diffraction peaks for MeO-MOC more closely resemble the gradual evolution found for the molecular porous carbon cycloparaphenylene, which also
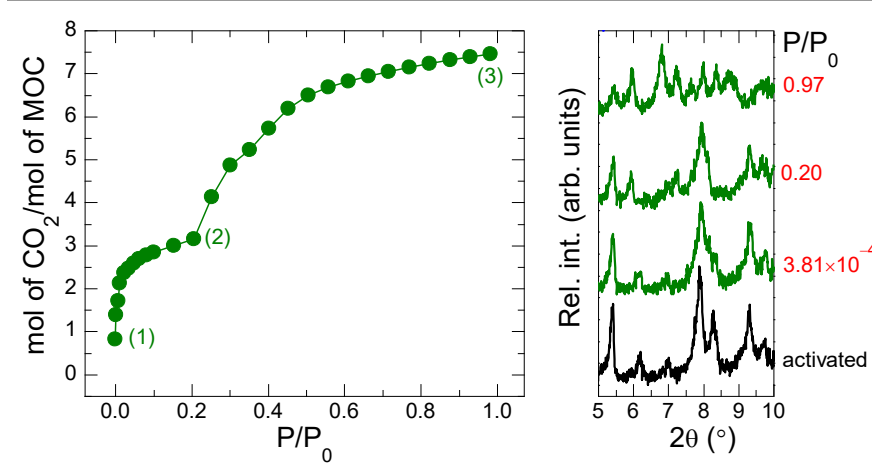

Fig. 4 (Left) Adsorption branch of the $\mathrm{CO}_{2}$ isotherm for MeO-MOC, collected at $195 \mathrm{~K}$. (right) Selected in situ powder X-ray diffraction data collected for MeO-MOC during the adsorption of $\mathrm{CO}_{2}$ at $195 \mathrm{~K}$ displayed a very broad hysteresis loop in response to $\mathrm{MeOH}$ and EtOH. ${ }^{15}$

PrO-MOC shows a low uptake of $\mathrm{N}_{2}$ at $77 \mathrm{~K}$ with a Type lisotherm. The adsorption branch very quickly enters a plateau corresponding to approximately one adsorbed molecule of $\mathrm{N}_{2}$ per MOC molecule, but does not show the step in adsorption found for MeO-MOC. PrO-MOC also displays a Type I gas sorption isotherm for $\mathrm{CO}_{2}$ at $195 \mathrm{~K}$ (see Fig. S16 and S17 for data in $\mathrm{cm}^{3} / \mathrm{g}$ ). The maximum uptake of $\mathrm{CO}_{2}$ measured at $P / P_{0} \approx 0.98$ was of $82.6 \mathrm{~cm}^{3} / \mathrm{g}$, which corresponds to approximately seven molecules of $\mathrm{CO}_{2}$ for each molecule of $\mathrm{MOC}$ (Fig. 3). The slight hysteresis that is observed between the adsorption and desorption branches of the gas uptake measurement is ascribed to slow kinetics of gas diffusion through the material, rather than cooperative phenomena. The overall uptake of $\mathrm{CO}_{2}$ by MeO-MOC, PrO-MOC, and the rigid phase of EtO-MOC, at 195 $\mathrm{K}$ and $P / P_{0} \approx 1$, is approximately the same, ranging from 82.6 to $85.0 \mathrm{~cm}^{3} / \mathrm{g}$ (see Fig. S17), suggesting that the capacity is determined by the intrinsic pore of the cages, which is identical in each case. The differences in the cooperativity of uptake highlight the effect of external functionalisation of the ligands.

In this paper, we have shown that by changing the functional group that is covalently attached to the lantern-type skeleton of a MOC then a range of gas sorption properties can be observed, from Type 1 isotherms to stepped gas adsorption that is concomitant to changes in the packing of the MOCs. Specifically, we observed the emergence and then disappearance of cooperative gas uptake as the length of the alkyl chain attached to the MOCs increased, suggesting that simple synthetic modifications of other MOCs could lead to similar gas sorption. Indeed, recent work has shown that alkyl chains can induce dynamic structural behaviour, even in the absence of $\pi-\pi$ stacking or hydrogen-bonding interactions. ${ }^{16}$ A further consideration to be explored is the impact of crystal size on cooperativity. Work on MOFs has shown that varying the crystallite size of the materials over the nanometer and micrometer length scales can lead to suppression or emergence of cooperative gas uptake. ${ }^{17}$ Given that the crystals of MeOMOC are in the micrometer size (Fig. S20), future work with these materials will also investigate the effect of downsizing the crystals on their cooperative behaviour.

\section{Conflicts of interest}

There are no conflicts to declare.

\section{Notes and references}

This work was supported by JSPS KAKENHI grant number 19H04575 (Coordination Asymmetry) and 19 K05495 (Kiban C). The authors thank the iCeMS Analysis Center for access to analytical instruments. Prof. Susumu Kitagawa (Kyoto University) is thanked for helpful discussion of the manuscript. $r$ Alan R. Kennedy (University of Strathclyde) is acknowledged for assistance with crystallography. 
1. (a) N. B. McKeown, J. Mater. Chem., 2010, 20, 10588-10597; (b) A I. Cooper, ACS Cent. Sci., 2017, 3, 544-553; (c) H. R. Green and G. O. Lloyd, in Functional Supramolecular Materials: From Surfaces to MOFs, ed. R. Banerjee, The Royal Society of Chemistry, 2017, ch. 9, pp. 297-324.

2. (a) T. Tozawa, J. T. A. Jones, S. I. Swamy, S. Jiang, D. J. Adams, S. Shakespeare, R. Clowes, D. Bradshaw, T. Hasell, S. Y. Chong, C. Tang, S. Thompson, J. Parker, A. Trewin, J. Bacsa, A. M. Z. Slawin, A. Steiner and A. I. Cooper, Nature Mater., 2009, 8, 973-978; (b) Y. Jin, B. A. Voss, A. Jin, H. Long, R. D. Noble and W. Zhang, J. Am. Chem. Soc., 2011, 133, 6650-6658; (c) G. Zhang, O. Presly, F. White, I. M. Oppel and M. Mastalerz, Angew. Chem. Int. Ed., 2014, 53, 1516-1520; (d) C. Zhang, Z. Wang, L. Tan, T.-L. Zhai, S. Wang, B. Tan, Y.-S. Zheng, X.-L. Yang and H.-B. Xu, Angew. Chem. Int. Ed., 2015, 54, 9244-9248; (e) S. Hong, M. R. Rohman, J. Jia, Y. Kim, D. Moon, Y. Kim, Y. H. Ko, E. Lee and K. Kim, Angew. Chem. Int. Ed., 2015, 54, 13241-13244; (f) G. Zhu, C. D. Hoffman, Y. Liu, S. Bhattacharyya, U. Tumuluri, M. L. Jue, Z. Wu, D. S. Sholl, S. Nair, C. W. Jones and R. P. Lively, Chem. Eur. J., 2016, 22, 10743-10747.

3. (a) M. Eddaoudi, J. Kim, J. B. Wachter, H. K. Chae, M. O'Keeffe and O. M. Yaghi, J. Am. Chem. Soc., 2001, 123, 4368-4369; (b) B. Moulton, J. Lu, A. Mondal and M. J. Zaworotko, Chem. Commun. 2001, 863-864; (c) J.-R. Li and H.-C. Zhou, Nature Chem., 2010, 2, 893; (d) S. Furukawa, N. Horike, M. Kondo, Y. Hijikata, A. CarnéSánchez, P. Larpent, N. Louvain, S. Diring, H. Sato, R. Matsuda, R. Kawano and S. Kitagawa, Inorg. Chem., 2016, 55, 10843-10846; (e) J. M. Teo, C. J. Coghlan, J. D. Evans, E. Tsivion, M. HeadGordon, C. J. Sumby and C. J. Doonan, Chem. Commun., 2016, 52, 276-279; (f) S. Mollick, S. Mukherjee, D. Kim, Z. Qiao, A. V. Desai, R. Saha, Y. D. More, J. Jiang, M. S. Lah and S. K. Ghosh, Angew. Chem. Int. Ed., 2019, 58, 1041-1045.

4. D. Holden, S. Y. Chong, L. Chen, K. E. Jelfs, T. Hasell and A. I. Cooper, Chem. Sci., 2016, 7, 4875-4879.

5. (a) O. Barreda, G. A. Taggart, C. A. Rowland, G. P. A. Yap and E. D. Bloch, Chem. Mater., 2018, 30, 3975-3978; (b) B. Teng, M. A. Little, T. Hasell, S. Y. Chong, K. E. Jelfs, R. Clowes, M. E. Briggs and A. I. Cooper, Cryst. Growth Des., 2019, 19, 3647-3651; (c) C. D. Charles and E. D. Bloch, Supramolecular Chemistry, 2019, 31, 508-513.

6. J. Park, Z. Perry, Y.-P. Chen, J. Bae and H.-C. Zhou, ACS Appl. Mater. Interfaces, 2017, 9, 28064-28068.

7. (a) J. T. A. Jones, D. Holden, T. Mitra, T. Hasell, D. J. Adams, K. E. Jelfs, A. Trewin, D. J. Willock, G. M. Day, J. Bacsa, A. Steiner and A. I. Cooper, Angew. Chem. Int. Ed., 2011, 50, 749-753; (b) A. Avellaneda, P. Valente, A. Burgun, J. D. Evans, A. W. MarkwellHeys, D. Rankine, D. J. Nielsen, M. R. Hill, C. J. Sumby and C. J. Doonan, Angew. Chem. Int. Ed., 2013, 52, 3746-3749; (c) T. Hasell, J. L. Culshaw, S. Y. Chong, M. Schmidtmann, M. A. Little, K. E. Jelfs, E. O. Pyzer-Knapp, H. Shepherd, D. J. Adams, G. M. Day and A. I. Cooper, J. Am. Chem. Soc., 2014, 136, 1438-1448; (d) S. Bera, K. Dey, T. K. Pal, A. Halder, S. Tothadi, S. Karak, M. Addicoat and R. Banerjee, Angew. Chem. Int. Ed., 2019, 58, 4243-4247.

8. T. Mitra, X. Wu, R. Clowes, J. T. A. Jones, K. E. Jelfs, D. J. Adams, A. Trewin, J. Bacsa, A. Steiner and A. I. Cooper, Chem. Eur. J., 2011, 17, 10235-10240.

9. (a) D. Zhao, D. Yuan, R. Krishna, J. M. van Baten and H.-C. Zhou, Chem. Commun., 2010, 46, 7352-7354; (b) E. J. Gosselin, C. A. Rowland, K. P. Balto, G. P. A. Yap and E. D. Bloch, Inorg. Chem. 2018, 57, 11847-11850; (c) A. López-Olvera, E. Sánchez-González, A. Campos-Reales-Pineda, A. Aguilar-Granda, I. A. Ibarra and B. Rodríguez-Molina, Inorg. Chem. Front., 2017, 4, 56-64; (d) S. A. Boer, K. F. White, B. Slater, A. J. Emerson, G. P. Knowles, W. A.
Donald, A. W. Thornton, B. P. Ladewig, T. D. M. Bell, M. R. Hill, A. L. Chaffee, B. F. Abrahams and D. R. Turner, Chem. Eur. J., 2019, 25, 8489-8493.

10. (a) S. Bourrelly, P. L. Llewellyn, C. Serre, F. Millange, T. Loiseau and G. Férey, J. Am. Chem. Soc., 2005, 127, 13519-13521; (b) H. J. Choi, M. Dincă and J. R. Long, J. Am. Chem. Soc., 2008, 130, 7848-7850; (c) Y. Du, B. Wooler, M. Nines, P. Kortunov, C. S. Paur, J. Zengel, S. C. Weston and P. I. Ravikovitch, J. Am. Chem. Soc., 2015, 137, 13603-13611; (d) J. A. Mason, J. Oktawiec, M. K. Taylor, M. R. Hudson, J. Rodriguez, J. E. Bachman, M. I. Gonzalez, A. Cervellino, A. Guagliardi, C. M. Brown, P. L. Llewellyn, N. Masciocchi and J. R. Long, Nature, 2015, 527, 357; (e) S. Krause, V. Bon, I. Senkovska, U. Stoeck, D. Wallacher, D. M. Többens, S. Zander, R. S. Pillai, G. Maurin, F.-X. Coudert and S. Kaskel, Nature, 2016, 532, 348; (f) E. J. Carrington, C. A. McAnally, A. J. Fletcher, S. P. Thompson, M. Warren and L. Brammer, Nature Chem., 2017, 9, 882; (g) A. Kultaeva, V. Bon, M. S. Weiss, A. Pöppl and S. Kaskel, Inorg. Chem., 2018, 57, 11920-11929; (h) A. Schneemann, P. Vervoorts, I. Hante, M. Tu, S. Wannapaiboon, C. Sternemann, M. Paulus, D. C. F. Wieland, S. Henke and R. A. Fischer, Chem. Mater., 2018, 30, 1667-1676; (i) Q.-Y. Yang, P. Lama, S. Sen, M. Lusi, K.-J. Chen, W.-Y. Gao, M. Shivanna, T. Pham, N. Hosono, S. Kusaka, J. J. Perry Iv, S. Ma, B. Space, L. J. Barbour, S. Kitagawa and M. J. Zaworotko, Angew. Chem. Int. Ed., 2018, 57, 5684-5689; (j) P. Sikiti, C. X. Bezuidenhout, D. P. van Heerden and L. J. Barbour, Inorg. Chem., 2019, 58, 8257-8262.

11. (a) M. Jaya Prakash, M. Oh, X. Liu, K. N. Han, G. H. Seong and M. S. Lah, Chem. Commun., 2010, 46, 2049-2051; (b) W. Lu, D. Yuan, A. Yakovenko and H.-C. Zhou, Chem. Commun., 2011, 47, 49684970; (c) V. Brega, M. Zeller, Y. He, H. Peter Lu and J. K. Klosterman, Chem. Commun., 2015, 51, 5077-5080; (d) D. Preston, K. F. White, J. E. M. Lewis, R. A. S. Vasdev, B. F. Abrahams and J. D. Crowley, Chem. Eur. J., 2017, 23, 10559-10567.

12. G. A. Craig, P. Larpent, S. Kusaka, R. Matsuda, S. Kitagawa and S. Furukawa, Chem. Sci., 2018, 9, 6463-6469.

13. A. L. Spek, Acta Cryst., 2009, D65, 148-155.

14. M. Thommes, K. Kaneko, V. Neimark Alexander, P. Olivier James, F. Rodriguez-Reinoso, J. Rouquerol and S. W. Sing Kenneth, pac, 2015, 87, 1051-1069.

15. H. Sakamoto, T. Fujimori, X. Li, K. Kaneko, K. Kan, N. Ozaki, Y. Hijikata, S. Irle and K. Itami, Chem. Sci., 2016, 7, 4204-4210.

16. E. Fernandez-Bartolome, J. Santos, A. Gamonal, S. Khodabakhshi, L. J. McCormick, S. J. Teat, E. C. Sañudo, J. S. Costa and N. Martín, Angew. Chem. Int. Ed., 2019, 58, 2310-2315.

17. (a) Y. Sakata, S. Furukawa, M. Kondo, K. Hirai, N. Horike, Y. Takashima, H. Uehara, N. Louvain, M. Meilikhov, T. Tsuruoka, S. Isoda, W. Kosaka, O. Sakata and S. Kitagawa, Science, 2013, 339, 193-196; (b) S. Krause, V. Bon, I. Senkovska, D. M. Többens, D. Wallacher, R. S. Pillai, G. Maurin and S. Kaskel, Nature Commun., 2018, 9, 1573; (c) S. Ehrling, I. Senkovska, V. Bon, J. D. Evans, P. Petkov, Y. Krupskaya, V. Kataev, T. Wulf, A. Krylov, A. Vtyurin, S. Krylova, S. Adichtchev, E. Slyusareva, M. S. Weiss, B. Büchner, T. Heine and S. Kaskel, J. Mater. Chem. A, 2019, 7, 21459-21475. 